\title{
Modelling of Inclusion Motion and Flow Patterns in Swirling Flow Tundishes with Symmetrical and Asymmetrical Structures
}

\author{
Qinfu HOU, ${ }^{1,2)}$ Qiang YUE, ${ }^{1)}$ Huanyang WANG, ${ }^{1)}$ Zongshu ZOU ${ }^{1)}$ and Aibing YU ${ }^{2)}$ \\ 1) School of Materials and Metallurgy, Northeastern University, Shenyang, 110004, China. E-mail: zouzs@mail.neu.edu.cn \\ 2) Centre for Simulation and Modelling of Particulate Systems, School of Materials Science and Engineering, University of \\ New South Wales, Sydney, NSW 2052, Australia.
}

(Received on October 4, 2007; accepted on March 31, 2008)

\begin{abstract}
Swirling flow tundish (SFT) has recently been developed as a new type of tundish. Its key mechanism is forming swirling flow to enhance inclusion removal from steel for high quality slab casting. This is achieved by guiding the liquid steel into the tundish through the tangential inlet of a cylindrical swirling chamber (SC). This can restrain and alleviate the turbulence of the impact zone. SC has been settled into two types of tundishes-originally symmetrical and asymmetrical. To understand the fundamentals, physical and mathematical modellings of this new process have been conducted in this work. Physical modellings are carried out with the utilization of an asymmetrical one-strand $1: 2.5$ and a symmetrical two-strand $1: 3$ scale models. The internal flow is measured by digital particle image velocimetry (DPIV). Numerical modelling is carried out in line with the physical modelling to examine the details of the flow patterns and rotational effect caused by the SC. The trajectories of non-metallic inclusion particles are also studied by discrete phase model (DPM) within the commercial CFD package environment, FLUENT. The mathematical model proposed is validated by comparing the predicted and measured residence time distribution and velocity fields. The results show that both originally symmetrical and asymmetrical flow fields have been changed to asymmetrical ones after setting SC into it. And the results show that the flow is slower behind the dam and weir. Examinations of the trajectories of inclusion particles suggest that the inclusion removal capacity of the SFT is higher than the tundish with a turbulence inhibitor (TI). From the separation ratio results, it can be seen that SFT has higher ability to remove small inclusion particles than a tundish with $\mathrm{Tl}$, which is of great significance especially for production of high-quality steel.
\end{abstract}

KEY WORDS: swirling flow tundish; inclusion removal; discrete phase model; digital particle image velocimetry; mathematical modelling; separation ratio.

\section{Introduction}

High steel qualities, energy-saving and cost-saving, together with environmental friendliness, are key issues in modern steel industry. ${ }^{1)}$ In traditional steelmaking, a tundish acts as a reservoir and distributor settled between ladle and caster. Recently, it also plays an important role in producing clean liquid steel by removing some unwanted inclusions. For this purpose, various types of flow control devices (FCD), such as dam, weir, turbulence inhibitor (TI) and stopper, have been developed in recent decades. ${ }^{2)}$ In addition, some new methods have also been proposed in continuous casting process, e.g. plasma heating ${ }^{3}$ ) for maintaining appropriate casting steel temperature and gas bubbling curtains $^{4)}$ to enhance inclusion removal by adhesion. Those methods have been used in asymmetrical one- and threestrand, and symmetrical two-, four-, six-strand tundishes. ${ }^{2)}$ In addition to those renovations, two typical types of tundishes are developed, the centrifugal flow tundish ${ }^{5)}$ (CFT) and the swirling flow tundish ${ }^{6}$ (SFT). The CFT developed by Kawasaki Steel (now JFE Steel Corporation) is a special one for inclusion removal. This type of tundish utilizes external electromagnetic force to rotate molten steel in a cylindrical tundish and to enhance inclusion removal by centrifugal force field. However, external electromagnetic apparatus must be used in this type of tundish, which increases the cost of production. Consequently, a huge amount of electricity is also consumed. It is neither environmentally friendly nor energy-saving. Despite the shortcomings of CFT, it was used in commercial production of high-quality stainless steel slabs after industrial tests at Chiba. The effect of CFT for inclusion removal has been verified, since the rotational field can enhance the removal of inclusion at 40-50 rpm. Numerical modelling has also been carried out to study the flow in $\mathrm{CFT}^{7)}$ using large eddy simulation model. Based on the idea of CFT, SFT is developed recently with a swirling chamber (SC) to produce rotational motion without extra energy consumption. While SFT can achieve similar metallurgical effects, external apparatus is no longer required to produce the centrifugal force field. In fact, the gravity potential energy of liquid steel in the ladle can be harnessed during continuous casting. By guiding the steel into a cylindrical chamber through its tangential inlet, the translational energy of steel liquid 
can be transformed into a rotational one. Hence, a rotational flow field is formed in the chamber. In this way, the SFT can fulfill the roles of both turbulence inhibition and inclusion removal. The variation of flow patterns in SC has been examined ${ }^{8)}$ in details by commercial software package. Different turbulent models have also been examined in SFT in recent numerical study ${ }^{9}$ by in-house code. And the influence of parameters of cylindrical SC on the whole flow field of SFT has also been studied by in-house code. ${ }^{10)}$ The inclusions less than several microns are very difficult to be removed by its very small flotation velocity (Stokes' velocity). CFT and SFT are good ways to increase the size of inclusions by collision and coalescence. Murakata ${ }^{11)}$ has carried out water model experiments to observe their collision behaviours. The collision rate of particles was quantified by direct observation of the particle collision behavior in a turbulent flow. However, for further analysis, the energy dissipation rate has to be obtained by numerical study.

In this work, physical and mathematical models are developed for one-strand and two-strand slab SFTs. The mathematical model is then validated by comparing overall residence time distribution (RTD) curves and more specific flow field measurements by digital particle image velocimetry (DPIV). Trajectories of inclusion particles are examined in those tundishes. Furthermore, the separation ratios of inclusion between one-strand SFT and a tundish with TI are compared. Based on these comparison and analysis of trajectories of inclusion particles, the positions of FCDs are adjusted to improve the separation ratio in SFT. The trajectory results of inclusion are necessary for further study of collision behaviour and coalescence phenomena.

\section{Model Description}

\subsection{Main Dimensions of Model}

Main features of the mathematical and cold physical models are shown in Fig. 1 for one-strand and two-strand tundishes, respectively. The relevant dimensions of onestrand SFT are given in Table 1. The coordinate system is shown in Fig. 1 for following discussion too. The structures of long shroud, inlet and swirling chamber are shown in Fig. 2 to illustrate the tangential position of inlet and the reason why there is a swirling flow.

\subsection{Numerical Method}

All simulations are carried out within commercial software package environment, FLUENT. The governing equations solved for flow fields are the standard conservation equations of mass and momentum. The equation for RTD is a normal species transportation equation. For trajectories of the inclusion, the discrete phase model (DPM) is employed with revised wall boundary conditions. The free surface and tundish walls have different boundary conditions (such as reflection and entrapment) for droplets/solid inclusion particles. Taking the ranges of diameter ${ }^{12)}$ and the shapes for different types of inclusions particles ${ }^{13)}$ into consideration, the boundaries and drag law for particles are then revised by user defined function and shape correction coefficient. During trajectory simulation, Stokes-Cunningham drag law is employed with Cunningham correction. Inclusions sometimes could be liquid phase. It is difficult to set the correc-

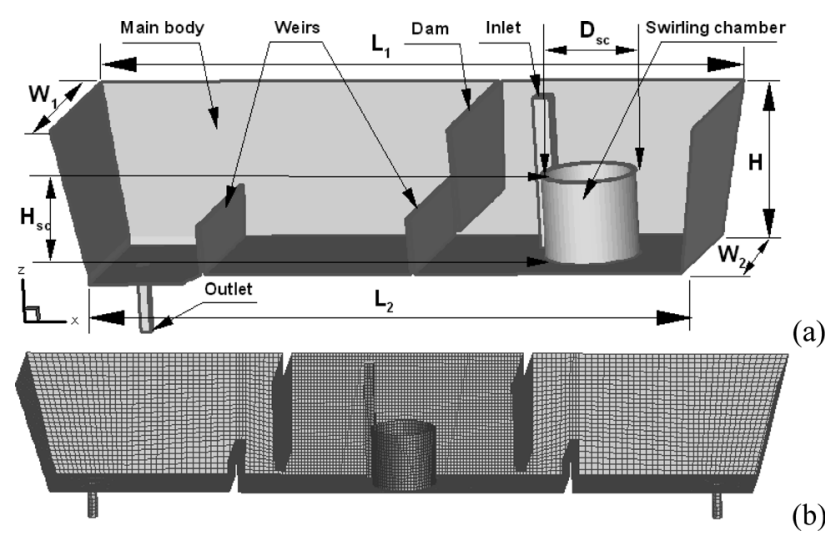

Fig. 1. Swirling flow tundish configuration and mesh: (a) onestrand, (b) two-strand.

Table 1. Dimensions of mathematical and physical model of one-strand SFT.

\begin{tabular}{lcccc}
\hline Dimensions & $L_{1}$ & $L_{2}$ & $W_{1}$ & $W_{2}$ \\
\hline Values, $\mathrm{mm}$ & 1800 & 1665 & 610 & 480 \\
\hline Dimensions & $H$ & $H_{\mathrm{sc}}$ & $D_{\mathrm{sc}}$ & $\Phi$ \\
\hline Values, $\mathrm{mm}$ & 420 & $90 \sim 260$ & $170 \sim 320$ & 30 \\
\hline
\end{tabular}
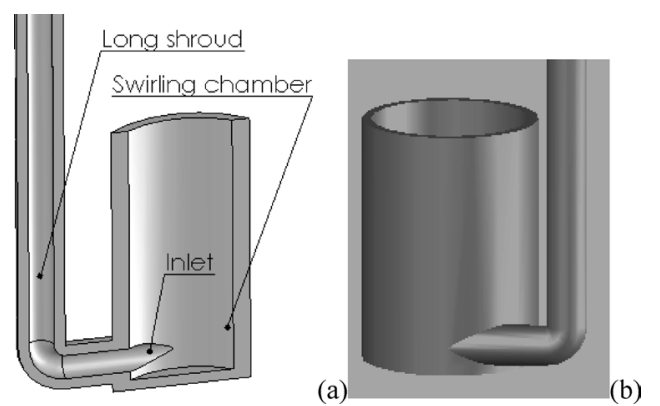

Fig. 2. Positions of long shroud, inlet and swirling chamber: (a) section view, (b) front view.

tion coefficient ${ }^{14)}$ exactly since droplets can move and deform continuously. While Sinha and Sahai ${ }^{15)}$ set both top free face and walls as trap boundary, Lopez-Ramirez ${ }^{16)}$ did not give the boundary conditions for inclusion. Zhang ${ }^{17)} \mathrm{di}-$ vided the tundish into two types of separation zones. Considering water modeling conditions, the walls are set as reflection boundary in this work for comparison of separation ratios of inclusion in SFT and a tundish with TI. Although most reports assume that the free surface is a trap boundary, there is a possibility of re-entrainment ${ }^{18)}$ to be considered.

Given that the fluid is incompressible (i.e. the density of water is constant at $998.2 \mathrm{~kg} / \mathrm{m}^{3}$ ), the modified conservation equations take the following forms.

Continuity equation:

$$
\frac{\partial\left(u_{i}\right)}{\partial x_{i}}=0
$$

Momentum equation:

$$
\rho u_{j} \frac{\partial u_{i}}{\partial x_{j}}=-\frac{\partial P}{\partial x_{i}}+\frac{\partial}{\partial x_{j}}\left[\mu_{\text {eff }}\left\{\frac{\partial u_{i}}{\partial x_{j}}+\frac{\partial u_{j}}{\partial x_{i}}\right\}\right] \ldots .
$$

Turbulence kinetic energy equation: 


$$
\frac{\partial\left(\rho u_{j} k\right)}{\partial x_{j}}=\frac{\partial}{\partial x_{j}}\left(\frac{\mu_{\text {eff }}}{\sigma_{k}} \times \frac{\partial k}{\partial x_{j}}\right)+G-\rho \varepsilon
$$

Dissipation rate equation:

$$
\frac{\partial\left(\rho u_{j} \varepsilon\right)}{\partial x_{j}}=\frac{\partial}{\partial x_{j}}\left(\frac{\mu_{\mathrm{eff}}}{\sigma_{\varepsilon}} \times \frac{\partial \varepsilon}{\partial x_{j}}\right)+\frac{\left(C_{1} G \varepsilon-C_{2} \rho \varepsilon^{2}\right)}{k} \ldots .
$$

Species transport equation:

$$
\frac{\partial C}{\partial t}+\frac{\partial}{\partial x_{i}}\left(u_{i} C\right)=\frac{\partial}{\partial x_{i}}\left(D_{\mathrm{e}} \frac{\partial C}{\partial x_{i}}\right)
$$

where,

$$
G=\mu_{\mathrm{t}} \frac{\partial u_{j}}{\partial x_{i}}\left(\frac{\partial u_{i}}{\partial x_{j}}+\frac{\partial u_{j}}{\partial x_{i}}\right)
$$

Effective viscosity:

$$
\mu_{\text {eff }}=\mu+\mu_{\mathrm{t}}=\mu+\rho C_{\mu} \frac{k^{2}}{\varepsilon}
$$

Effective mass-diffusion coefficient, which depends on the fluid flow field, ${ }^{19)}$ can be calculated through:

$$
\frac{\mu_{\text {eff }}}{\rho D_{\mathrm{e}}} \approx 1
$$

The constants of $k-\varepsilon$ two-equation turbulence model ${ }^{20)}$ are $C_{1}=1.44, C_{2}=1.92, C_{\mu}=0.09, \sigma_{k}=1.0$, and $\sigma_{\varepsilon}=1.3$.

Boundary conditions for flow field calculations are similar to those used by others researchers ${ }^{21)}$ for steady 3D isothermal flow in tundish.

\subsection{Physical Model}

The physical model is created according to real units of industrial tundishes under similarity principle. The selected physical scale factor $\lambda$ is $1: 2.5$ for one-strand and $1: 3$ for two-strand, respectively. The structures of water models for experiments are similar with numerical ones (as shown in Fig. 1). It is made of transparent acrylaglas. Water model experiments are carried out at $Q_{1,2,3}=2,2.5,3 \mathrm{Nm}^{3} / \mathrm{h}$ for one-strand SFT and $Q=3.2 \mathrm{Nm}^{3} / \mathrm{h}$ for two-strand SFT.

\section{Results and Discussion}

\subsection{Numerical Model Validation}

RTD is the most common measure to estimate the particle separation and to analyze the flow conditions. The experimental results are obtained by pulse tracer addition technique. The predicted results are calculated out by twostep simulation. The first step is to calculate the steady flow fields. The second step is to solve the species transport equation using unsteady solver based on the steady flow results of the first step. Figure 3 shows the comparison of measured and predicted results with the same conditions $\left(Q_{2}, D_{2}, H_{5}\right)$.

The comparison of flow fields is also carried out and given in Fig. 4. The magnitude and distribution of velocity field are similar, respectively. The measured result is obtained by using DPIV with a kind of tracer particle with

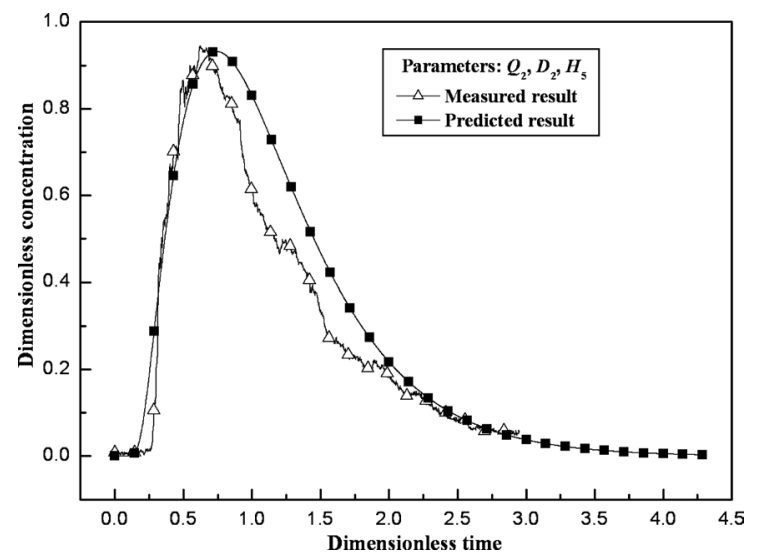

Fig. 3. Comparison of RTD.

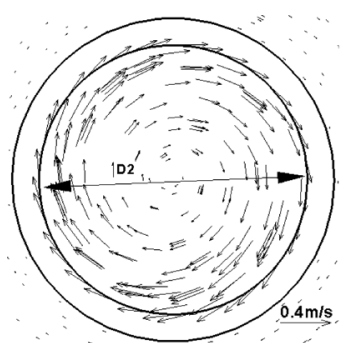

(a)

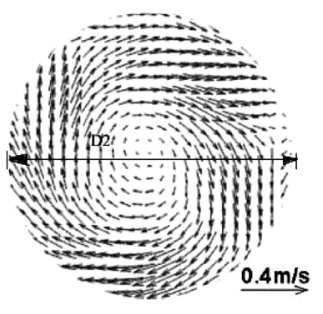

(b)
Fig. 4. Comparison of velocity fields: (a) predicted result, (b) measured result.

slightly higher density than water, $1050 \mathrm{~kg} / \mathrm{m}^{3}$. The tracer particles' diameters are in the range of $1-5 \mu \mathrm{m}$. This method has been widely used to measure flow fields. The configuration of the apparatus can be found elsewhere. $^{4,22-24)}$

\subsection{Asymmetrical Flow Field}

The asymmetrical flow field can be seen in Fig. 4 and Fig. 5 in impact zone (the area below the inlet) and in areas behind the dam and weirs. It is a $x y$-plane section at height of $z=200 \mathrm{~mm}$ for one-strand tundish and $z=270 \mathrm{~mm}$ for two-strand to the bottom of tundish. The rotational and higher velocity flows are mostly confined in SC domain. The slow and uniform flow behind the wall is beneficial to flotation of inclusion to the top slag-steel interface, which is the main mechanism for inclusion removal. It is apparent that the originally symmetrical flow field (Fig. 5(b)) is changed to asymmetrical one (Fig. 5(c)) after introducing of SC.

\subsection{Influence of Swirling Chamber Geometry}

For the study of the influence of SC geometrical parameters on rotational speed, a series of cylindrical SCs are employed in one-strand SFT and their dimensions are given in Table 2.

Swirling chamber diameter has great influence on axial velocity distribution in SC (shown in Fig. 6). The velocity distributions have downward velocity in the center and upward velocity near the wall of SC for both two diameters $\left(D_{3}, D_{5}\right)$. With the smaller diameter $\left(D_{3}\right)$, the axial velocity distribution in $x$-direction is similar to that in $y$-direction. However, with the larger diameter $\left(D_{5}\right)$, these distributions 

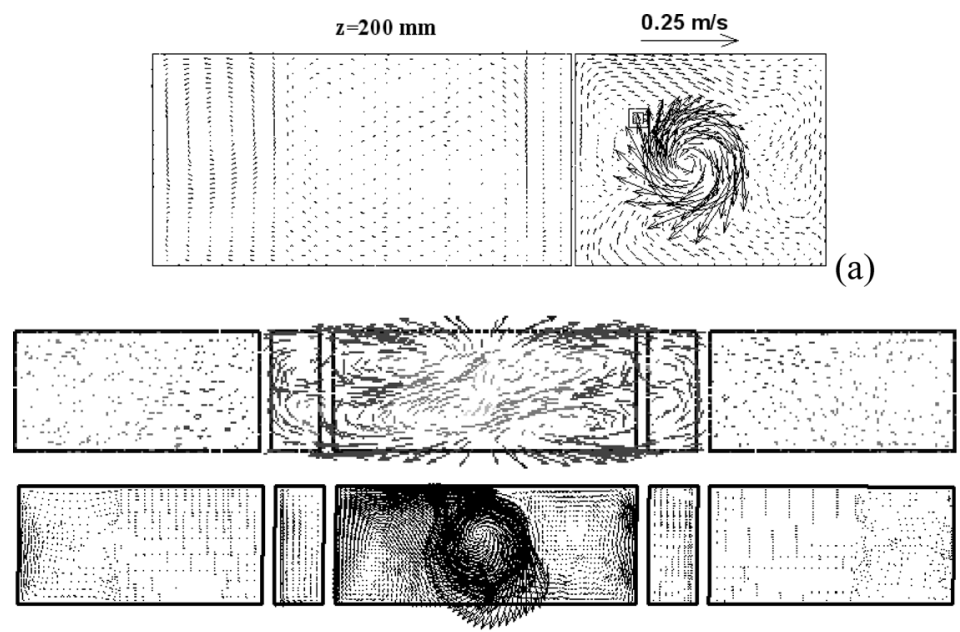

(b)

(c)

Fig. 5. Flow fields of (a) one-strand at $Q_{1}, H_{4}, D_{3}$, (b) symmetrical two-strand tundish, (c) asymmetrical two-strand SFT.

Table 2. Swirling chamber dimensions.

\begin{tabular}{cccccc}
\hline$D_{\text {sc }}$ & $D_{1}$ & $D_{2}$ & $D_{3}$ & $D_{4}$ & $D_{5}$ \\
\hline $\mathrm{mm}$ & 170 & 200 & 240 & 280 & 320 \\
\hline$H_{\mathrm{sc}}$ & $H_{1}$ & $H_{2}$ & $H_{3}$ & $H_{4}$ & $H_{5}$ \\
\hline $\mathrm{mm}$ & 90 & 140 & 180 & 220 & 260 \\
\hline
\end{tabular}

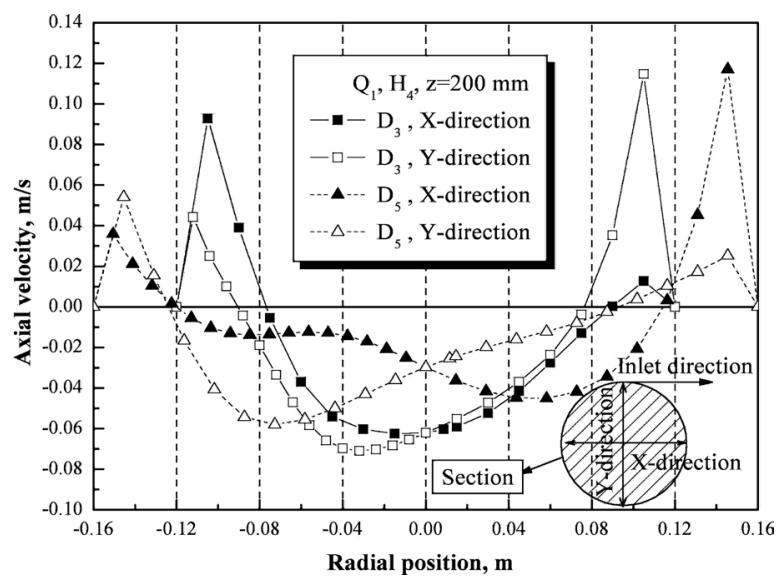

Fig. 6. Influence of $\mathrm{SC}$ parameters on velocity distribution.

are different. In the range of $-0.12-0 \mathrm{~m}$, the value of velocity in $x$-direction is less than that in $y$-direction. In the range of $0-0.12 \mathrm{~m}$, there is a reverse trend.

Through the results of numerical simulations and measurements, it is shown that the maximum rotational speed obtained in SC is $\omega=70 \mathrm{rpm}$, which is comparable to the speed of 40-50 rpm obtained from CFT. ${ }^{25)}$ According to the similarity criterion $R t\left(R t=l^{3} Q^{-1} \omega\right)$, the maximum rotational speed that can be achieved is $44 \mathrm{rpm}$ in real unit. The variation trend of rotational speed with diameter and height of SC can be found in another publication. ${ }^{6}$ )

\subsection{Path Lines of Flow Field}

The path lines of fluid in one-strand SFT, tundish with TI and two-strand SFT are given in Fig. 7. It shows that the path lines in SFT are much more complicated than those of the tundish with TI in impact zone. The chance for inclusion collision and coalescence will be increased by SC. It should be pointed out that some path lines of SFT that go out of SC go back into SC again. Since the path lines be-

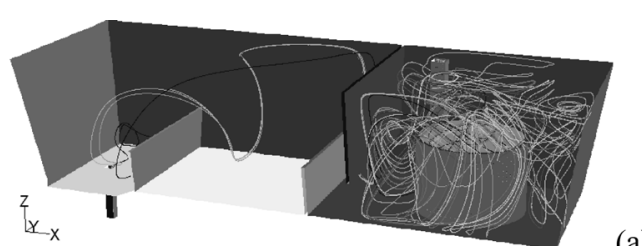

(a)

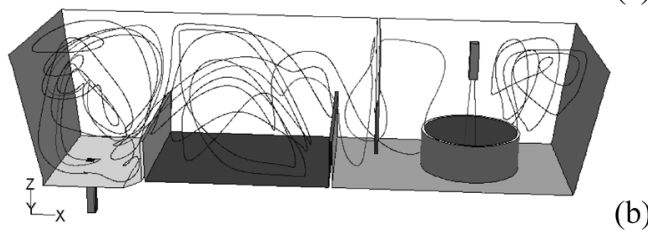

(b)

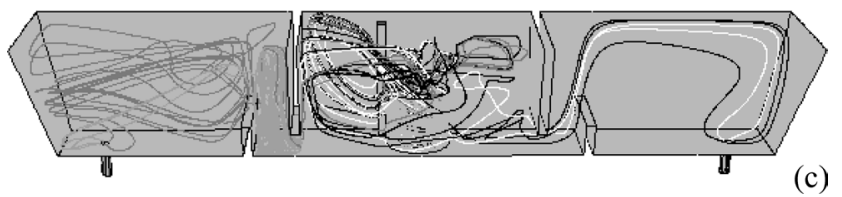

(c)

Fig. 7. Path lines of flow fields in (a) one-strand SFT, (b) tundish with TI, (c) two-strand SFT.

come longer in SFT, the residence of fluid will be extended actually to some degree.

\subsection{Similarity Analysis of Inclusion Particle}

The non-metallic inclusion particles are lighter than molten steel in real unit and, thus, will rise up to the slag-steel interface. Because the inclusion in tundish can reach its Stokes' velocity in extremely short time, the flotation velocity of an inclusion is determined as the same as its Stokes' velocity.

Unfortunately, in physical modelling, it is difficult to find particles with identical density and diameter to the real situation. Therefore, it is necessary to analyze the similarity of particles in model and real tundishes. Sahai and $\mathrm{Emi}^{26)}$ have analyzed the similarity of particles. Assuming that the kinematical viscosity of water at room temperature is the same as that of steel at $1873 \mathrm{k}$, one obtains

$$
\frac{R_{\text {inc, } \mathrm{m}}^{2}}{R_{\text {inc, } \mathrm{p}}^{2}} \cdot \frac{1-\rho_{\text {inc, } \mathrm{m}} / \rho_{\mathrm{w}}}{1-\rho_{\text {inc, } \mathrm{p}} / \rho_{\mathrm{st}}}=\sqrt{\lambda}
$$

For mathematical modelling, $R_{\text {inc,m }}$ can be chosen to be the same as $R_{\text {inc,p }}$. Consequently, $\rho$ can be calculated as 640 
$\mathrm{kg} / \mathrm{m}^{3}$ for the inclusion density of $3000 \mathrm{~kg} / \mathrm{m}^{3}$ in real condition according to the similarity criterion (Eq. (9)).

In fact, a similarity criterion can be obtained by dimensional analysis. Taking kinematical viscosity $\mu$, density $\rho$, the difference of density $\left(\rho_{1}-\rho_{\text {inc }}\right)$, radius $r$, relative velocity $u$ and gravitational acceleration $g$ into consideration, three dimensionless groups can be formed, $\mathrm{Re}^{-1}, \mathrm{Fr}^{-1}$ and $\left(\rho_{1}-\rho_{\mathrm{s}}\right) / \rho_{1}$. According to Buckingham's $\Pi$ Theorem, the group of $\operatorname{ReFr}^{-1}\left(\rho_{1}-\rho_{\mathrm{s}}\right) / \rho_{1}$ is actually the same as the analysis result from Sahai and Emi.

\subsection{Trajectories of Inclusion Particles}

Different densities of inclusion were used in the literatures, e.g. $3500 \mathrm{~kg} / \mathrm{m}^{3}$ for spherical particles and 5000 $\mathrm{kg} / \mathrm{m}^{3}$ for clusters, ${ }^{16)} 2700 \mathrm{~kg} / \mathrm{m}^{3}$ for spherical inclusions. ${ }^{15)}$ Three densities are considered in this work for mathematical model simulation $\left(400,500,600 \mathrm{~kg} / \mathrm{m}^{3}\right)$ to examine the influence of density on separation ratio of inclusion.

To calculate inclusion separation ratio, the injection of particles is set. The original injection position is on the inlet surface. The injected particles are set with different diameters and densities. 2000 particles are released each time and their trajectories are calculated out with discrete random walk model. Each injection condition is repeated five times and then the total separation ratios are calculated. Twenty representative trajectories of inclusion particles in one-strand SFT, a tundish with TI and two-strand SFT are shown in Fig. 8. It can be seen that the trajectories for the same kind of inclusion particle are different. In the tundish with SC, most particles have longer trajectories in the impact zone than those in the tundish with TI. This can enhance the removal of inclusion to slag-steel interface. Moreover, in the zone above the outlet, it can be seen that inclusion particles in the tundish with TI have greater possibility to go into mold than those in the tundish with SC. From Fig. 8(c), one can see that the trajectories above the outlet are different for the left and right zones to the SC. The position of SC should thus be optimized for uniform quality of casting steel out of each outlet.

\subsection{Comparison of Removal Possibility}

The influence of particle density on separation ratio is given in Fig. 9. It can be seen that the difference of density has a minor influence on separation ratio within the density range of $400-600 \mathrm{~kg} / \mathrm{m}^{3}$. Moreover, according to the weight of inclusion distribution (shown in Fig. 10) from experimental samples, particles larger than $75 \mu \mathrm{m}$ have little significance and can be neglected during simulation process.

For larger diameters of particle $(50 \mu \mathrm{m})$, the separation ratio of tundish with TI is higher than that of SFT. The reason for this is the short distance between the dam and the first weir or between dam and SC which can be seen from the trajectories shown in Figs. 11(a), 11(b). Because of these narrow spaces, the upward flow is very quick and it can be reflected instantly downward. Consequently, the entrainment possibility of inclusion particles to slag-steel interface is decreased for inclusion particles. The SFT has been revised to alleviate this phenomenon. Both of the distances between the dam and the first weir and between the weir and SC have been extended $100 \mathrm{~mm}$ in one simulation. It can be seen from Fig. 11(c) that the strong upward flow is

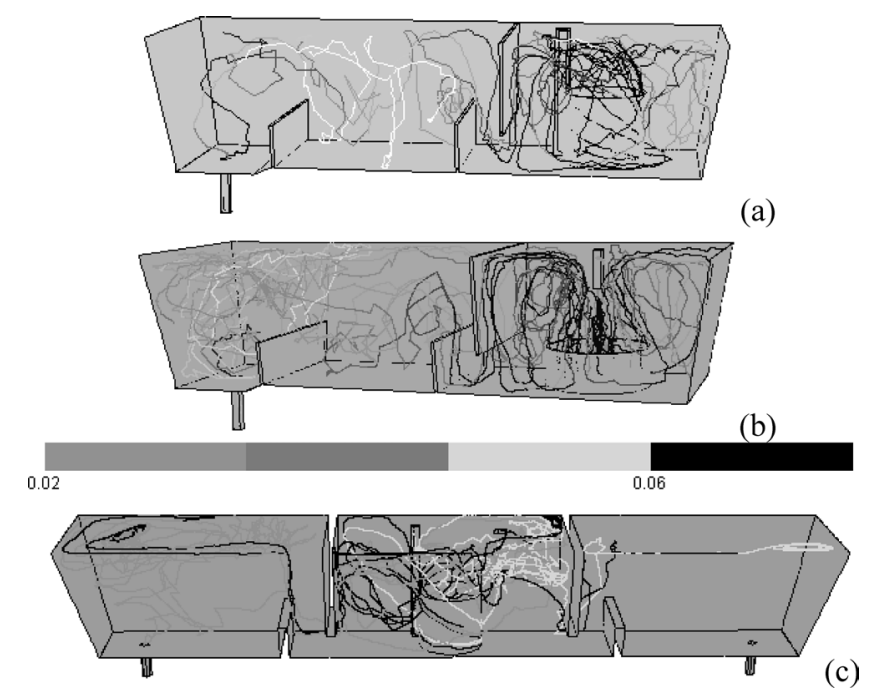

Fig. 8. Trajectories of particles in tundishes: (a) one-strand SFT $\left(\mathrm{H}_{4}, \mathrm{D}_{3}, \mathrm{Q}_{1}, 20 \mu \mathrm{m}, 500 \mathrm{~kg} / \mathrm{m}^{3}\right)$, (b) TI $\left(\mathrm{H}_{4}, \mathrm{D}_{3}, \mathrm{Q}_{1}\right.$, $20 \mu \mathrm{m}, 500 \mathrm{~kg} / \mathrm{m}^{3}$ ), (c) two-strand tundish with different particle diameters $\left(\mathrm{Q}_{2}, \mathrm{H}_{3}, \mathrm{D}_{2}, 3000 \mathrm{~kg} / \mathrm{m}^{3}\right)$.

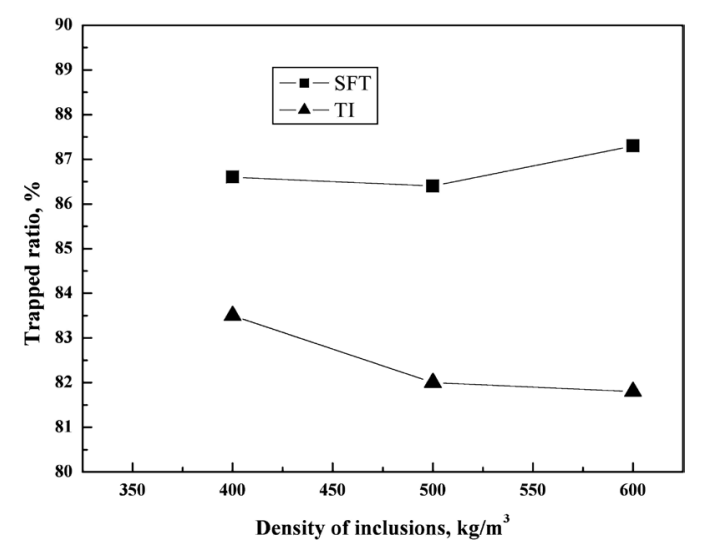

Fig. 9. Relationships between removal ratio and density of inclusion particles.

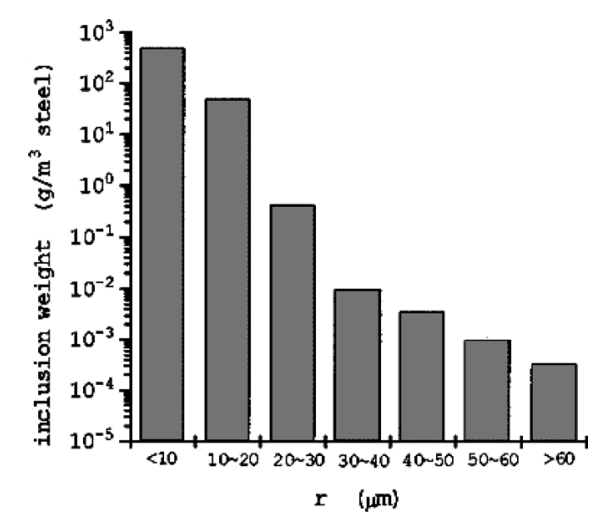

Fig. 10. Size distribution of inclusion in weight extracted from steel by Slimes method. ${ }^{17)}$

weakened. As a result, the separation ratios of inclusions are improved as shown in Table 3, particularly for the $20 \mu \mathrm{m}$ diameter particles.

It should be pointed out here that the original positions of flow control devices were optimized for tundish with TI. However, the results show that they are no more suitable for SFT. For different design of flow control schemes, their positions should be relocated for optimum operation. 

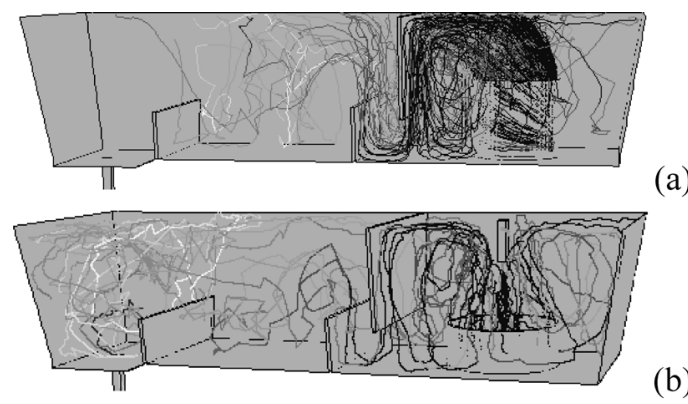

a)

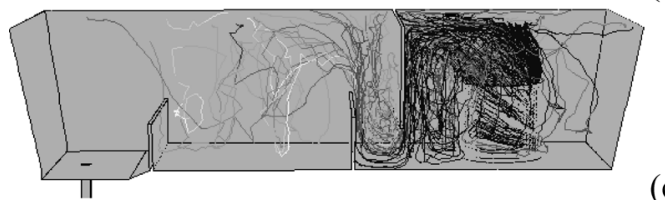

(c)

Fig. 11. Trajectories of particles in (a) SFT, (b) TI, (c) adjusted SFT.

Table 3. Separation ratio in different types of tundish $\left(\rho=500 \mathrm{~kg} / \mathrm{m}^{3}\right)$.

\begin{tabular}{ccccc}
\hline Diameter, $\mu \mathrm{m}$ & 20 & 50 & 60 & 80 \\
Tundish & & & & \\
\hline TI, \% & 82.00 & 94.95 & 97.27 & 99.10 \\
SFT, \% & 86.40 & 92.30 & 94.09 & 97.67 \\
Adjusted SFT, \% & 89.85 & 93.68 & 95.19 & 97.95 \\
\hline
\end{tabular}

\section{Conclusion}

A new swirling flow tundish has been developed and modelled by physical and mathematical methods. The numerical model is validated by RTD and flow field respectively. The flow fields, the motion and separation of inclusions are examined too. The conclusion can be drawn as follow.

(1) Flow fields in SFT are asymmetrical for both onestrand and two-strand. Because of the introduction of SC, the inlet is not set in a symmetrical position as usual. Hence, the whole flow field is changed to be more complicated and not symmetrical.

(2) Inclusions have more chance of flotation to slagsteel interface in SFT than the tundish with TI. The separation ratios show that SFT have greater ability to remove inclusion than the tundish with TI. Especially for small particle, for example $20 \mu \mathrm{m}$, SFT's advantage is evident. This is especially important for producing high quality steel.

(3) For different designs of tundish, the positions of all flow control devices and SC should be relocated for optimum metallurgical effects.

\section{Acknowledgement}

One of the authors (Q. F. Hou) would like to make grateful acknowledgements to the Centre for Simulation and Modelling of Particulate Systems (SIMPAS) for the visiting fellowship.

\section{Nomenclature}

$C: \quad$ Concentration of tracer $\left(\mathrm{kg} / \mathrm{m}^{3}\right)$

$D_{\mathrm{e}}$ : Effective turbulent mass diffusivity $\left(\mathrm{m}^{2} / \mathrm{s}\right)$

$D_{\text {sc }}$ : Diameter of swirling chamber ( $\left.\mathrm{mm}\right)$

$H$ : Height of tundish (mm)

$H_{\text {sc }}$ : Height of swirling chamber (mm) $k$ : Turbulent kinetic energy $(\mathrm{J} / \mathrm{kg})$

$L_{1}$ : Top length of tundish (mm)

$L_{2}$ : Bottom length of tundish (mm)

$P$ : $\quad$ Pressure $(\mathrm{Pa})$

$Q$ : Inlet flowrate $\left(\mathrm{Nm}^{3} / \mathrm{h}\right)$

$R$ : Radius of inclusion

$R t$ : Rotational similarity criterion

$u_{i}$ : Velocity in the $x_{i}$ direction $(\mathrm{m} / \mathrm{s})$

$W_{1}$ : Top width of tundish (mm)

$W_{2}$ : Bottom width of tundish (mm)

$x_{i}$ : Cartesian coordinates vector

$\Phi: \quad$ Inlet diameter (mm)

$\varepsilon$ : Dissipation rate of kinetic energy $\left(\mathrm{m}^{2} / \mathrm{s}^{3}\right)$

$\rho:$ Density $\left(\mathrm{kg} / \mathrm{m}^{3}\right)$

$\mu$ : Molecular viscosity of fluid $(\mathrm{Pa} \cdot \mathrm{s})$

$\mu_{\mathrm{t}}$ : Turbulent viscosity of fluid $(\mathrm{Pa} \cdot \mathrm{s})$

$\mu_{\text {eff }}$ : Effective viscosity of fluid $(\mathrm{Pa} \cdot \mathrm{s})$

$\omega$ : Rotational speed (rpm)

Subscript

inc: Inclusion

m: Model

$\mathrm{p}$ : Prototype

st: Steel

w: Water

\section{REFERENCES}

1) L. F. Zhang and B. G. Thomas: ISIJ Int., 43 (2003), 271.

2) D. Mazumdar and R. I. L. Guthrie: ISIJ Int., 39 (1999), 524.

3) J. D. J. Barreto-Sandoval, A. W. D. Hills, M. A. Barron-Meza and R. D. Morales: ISIJ Int., 36 (1996), 1174.

4) A. Ramos-Banderas, R. D. Morales, L. Garcia-Demedices and M. Diaz-Cruz: ISIJ Int., 43 (2003), 653.

5) Y. Miki, S. Ogura and T. Fujii: Kawasaki Steel Tech. Rep., (1996), 67.

6) Z. Zou, Q. Hou, S. Kuang and H. Li: SCANMET II-2nd Int. Conf. on Process, MEFOS, Luleå, Sweden, (2004).

7) F. Wang, B. Li and F. Tsukihashi: ISIJ Int., 47 (2007), 568.

8) Q. F. Hou and Z. S. Zou: Kang T'ieh/Iron Steel (Peking), 40 (2005), 33.

9) Q. Hou and Z. Zou: ISIJ Int., 45 (2005), 325

10) Q. Hou and Z. Zou: Steel Res. Int., 76 (2005), 726.

11) Y. Murakata, M. G. Sung, K. Sassa and S. Asai: Tetsu-to-Hagané, 92 (2006), 579.

12) V. Chevrier and A. W. Cramb: Scand. J. Metall., 34 (2005), 89.

13) K. Beskow, J. Jia, C. H. P. Lupis and S. C. Du: Ironmaking Steelmaking, 29 (2002), 427.

14) A. Haider and O. Levenspiel: Powder Technol., 58 (1989), 63.

15) A. K. Sinha and Y. Sahai: ISIJ Int., 33 (1993), 556.

16) S. Lopez-Ramirez, J. D. J. Barreto, J. Palafox-Ramos, R. D. Morales and D. Zacharias: Metall. Mater. Trans. B, 32B (2001), 615.

17) L. F. Zhang, S. Taniguchi and K. K. Cai: Metall. Mater. Trans. B, 31B (2000), 253.

18) D. Bouris and G. Bergeles: Metall. Mater. Trans. B, 29B (1998), 641.

19) Y. He and Y. Sahai: Metall. Trans. B, 18B (1987), 81.

20) B. E. Launder and D. B. Spalding: Comp. Meth. Appl. Mech. Eng., 3 (1974), 269.

21) A. Kumar, S. C. Koria and D. Mazumdar: ISIJ Int., 44 (2004), 1334.

22) H. J. Odenthal, R. Bolling, H. Pfeifer, J. F. Holzhauser and F. J. Wahlers: Steel Res., 72 (2001), 466.

23) H.-J. Odenthal, H. Pfeifer and M. Klaas: Steel Res., 71 (2000), 210.

24) A. Kumar, D. Mazumdar and S. C. Koria: Metall. Mater. Trans. B, 36B (2005), 777.

25) M. Yuji, O. Sigeru and F. Tetsuya: Kawasaki Steel Tech. Rep., (1996), 67

26) Y. Sahai and T. Emi: ISIJ Int., 36 (1996), 1166. 